\title{
The Function of $\mathrm{Ca}(\mathrm{OH})_{2}$ and $\mathrm{Na}_{2} \mathrm{CO}_{3}$ as Additive on the Reduction of High-Phosphorus Oolitic Hematite-coal Mixed Pellets
}

\author{
Wen YU, Tichang SUN, ${ }^{*}$ Jue KOU, Yuxia WEl, Chengyan XU and Zhenzhen LIU \\ School of Civil and Environment Engineering, University of Science and Technology Beijing, Beijing, 100083 China. \\ (Received on October 30, 2012; accepted on December 12, 2012)
}

\begin{abstract}
A process with coal-based direct reduction followed by magnetic separation is presented for recovering metallic iron from high-phosphorus oolitic hematite in this study. $\mathrm{Ca}(\mathrm{OH})_{2}$ and $\mathrm{Na}_{2} \mathrm{CO}_{3}$ were used as additives in the reduction roasting. A Direct Reduction Iron (DRI) with 93.28 mass\% Fe, and 0.07 mass \% P can be obtained at a recovery percentage of 92.30 mass $\%$ under optimal conditions. The mechanisms of $\mathrm{Ca}(\mathrm{OH})_{2}$ and $\mathrm{Na}_{2} \mathrm{CO}_{3}$ were investigated by XRD and SEM with EDS. It showed that fluorapatite was reduced to $\mathrm{P}$ smelt into metallic iron without additives while the hematite was reduced. The addition of $\mathrm{Ca}(\mathrm{OH})_{2}$ can not only inhibit the reduction of fluorapatite but also promote the reduction of hematite. $\mathrm{Na}_{2} \mathrm{CO}_{3}$ can promote the separation of iron from slag, meanwhile it may also inhibit the reduction of fluorapatite at the presence of 15 mass $\% \mathrm{Ca}(\mathrm{OH})_{2}$. Under optimal conditions, phosphorus remained as fluorapatite in the slag and can be removed by grinding and magnetic separation.
\end{abstract}

KEY WORDS: high-phosphorus oolitic hematite; fluorapatite; $\mathrm{Ca}(\mathrm{OH})_{2} ; \mathrm{Na}_{2} \mathrm{CO}_{3}$; direct reduction roasting; metallic iron.

\section{Introduction}

The feed for iron and steel making must be upgraded through a series of physical separation processes including crushing, grinding and separation, because both blast furnace and direct reduction reactors cannot tolerate high volumes of slag. ${ }^{1)}$ In addition, the content of harmful impurity such as phosphorus must be strictly controlled since too high phosphorus will bring about the welding problem of steel. ${ }^{2)}$ However, there are many iron ores so fine-grained that it is impractical to grind them to a fine enough size to separate the iron oxides from the gangue, thus these iron ores are not utilized now. Along with the fast depletion of easy-to-process iron ores, exploitation of refractory iron ores becomes more and more important all over the world, especially in China. China imports hundreds of millions of tons of iron ore every year. ${ }^{3)}$ At the same time, China has many iron ore deposits which are difficult to process. The Ningxiang type high-phosphorus oolitic hematite ore, which typically contains 30 mass $\%$ to 45 mass $\% \mathrm{Fe}$ and 0.4 mass $\%$ $1.1 \mathrm{mass} \% \mathrm{P}$, is one of the refractory iron ores. Since the unique internal structure of the ore that the iron oxides, fluorapatite and chamosite are so intimately intermixed that it is not practical to obtain qualified iron concentrate by conventional mineral processing methods. ${ }^{4)}$

Recent research shows that, it is feasible to recover metallic iron from refractory ore and other iron-containing materials by coal-based direct reduction - magnetic separation process. ${ }^{5-7)}$ Some researches have been reported on coal-

* Corresponding author: E-mail: suntc@ces.ustb.edu.cn DOI: http://dx.doi.org/10.2355/isijinternational.53.427 based direct reduction of high-phosphorus oolitic hematite. ${ }^{8-11)}$ It was reported that the Direct Reduction Iron (DRI), assaying more than 90 mass $\% \mathrm{Fe}$, less than 0.1 mass $\%$ $\mathrm{P}$ with an iron recovery of about 80 mass $\%$, can be obtained at the optimum conditions. ${ }^{8-10)}$ These researches were conducted below $1150^{\circ} \mathrm{C}$, because higher temperature will lead to the P content of DRI increasing. The cause for this is that the fluorapatite in the raw ore will be reduced to elemental $\mathrm{P}$ which can be smelt into metal iron. However, because the reduction of hematite was not complete under low temperatures, iron lost into the tailing in the form of fayalite and hercynite. In order to promote the recovery of iron, 20 mass $\%$ 30 mass $\%$ additives, sodium salt or calcium salt, must be added in the reduction roasting. $\mathrm{Ca}(\mathrm{OH})_{2}$ and $\mathrm{Na}_{2} \mathrm{CO}_{3}$ are used as additives in the direct reduction process to increase the recovery of iron, their effects on promoting the reduction of iron oxides and improving the separation of iron from slag have been proved. ${ }^{10,11)}$ However, their action mechanisms for dephosphorization are not completely clarified, especially at high temperature which fluorapatite can be reduced by coal.

In this study, the direct reduction of high-phosphorus oolitic hematite-coal composite pellets were conducted at $1200^{\circ} \mathrm{C}, \mathrm{Ca}(\mathrm{OH})_{2}$ is used alone or in combination with $\mathrm{Na}_{2} \mathrm{CO}_{3}$ as additives in the process and their action mechanisms of dephosphorization were studied.

\section{Experimental}

\subsection{Raw Materials}

The high phosphorus iron ore sample used in this work is 
a typical Ningxiang high phosphorus oolitic hematite from Hubei Province, China. The results of chemical analysis of raw ore show that the iron content of raw ore is 43.58 mass $\%$, the content of phosphorus is 0.83 mass $\%$, and the contents of acid gangue including $\mathrm{SiO}_{2}$ and $\mathrm{Al}_{2} \mathrm{O}_{3}$ are 17.10 mass\% and 9.28 mass\% respectively. The X-Ray Diffraction (XRD) analysis of the raw iron found that iron mainly occurs in the form of hematite, with impurities including quartz, chlorite and fluorapatite, as shown in Fig. 1. The photomicrograph of raw ore is shown in Fig. 2. It can be seen clearly from Fig. 2 that hematite together with chlorite and fluorapatite builds the concentric shell of oolites, the iron oxides and gangue minerals are intimately intergrowth.

The coal used as reductant in this study was obtained from Ningxia Province in China. The results of industrial analysis (air dry) of the coal were 11.77 mass \% moisture, 19.90 mass $\%$ ash, 28.18 mass $\%$ volatiles, 51.92 mass $\%$ fixed carbon. The raw ore and coal were crushed to 100 mass $\%$ passing $1 \mathrm{~mm}$. $\mathrm{Ca}(\mathrm{OH})_{2}$ and $\mathrm{Na}_{2} \mathrm{CO}_{3}$ used as additives in the experiments were analytical reagent (AR) grade.

\subsection{Experimental Procedure}

The pellets were produced by the following procedures: first, $20 \mathrm{~g}$ iron ore, a certain amount of coal, additives and water were mixed together, and then the mixture was pressed to form pellets using an die with a size of $30 \mathrm{~mm}$ diameter.

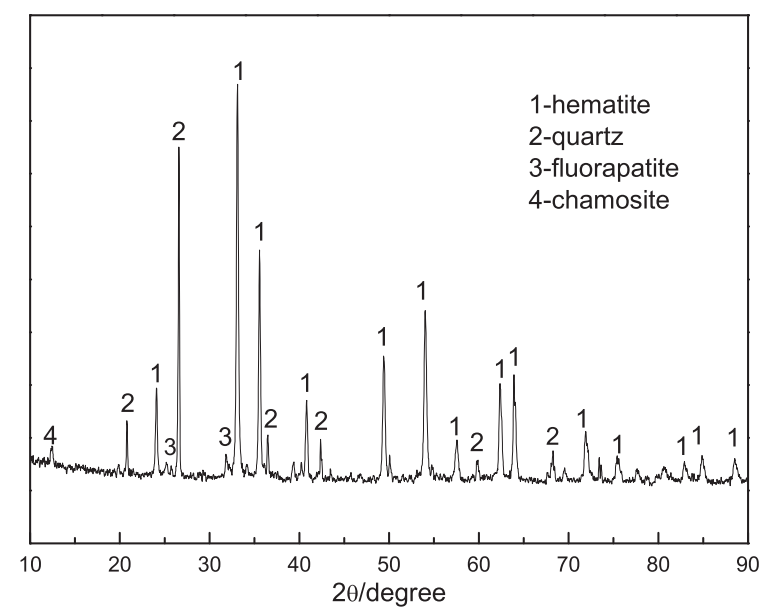

Fig. 1. XRD pattern of raw ore.

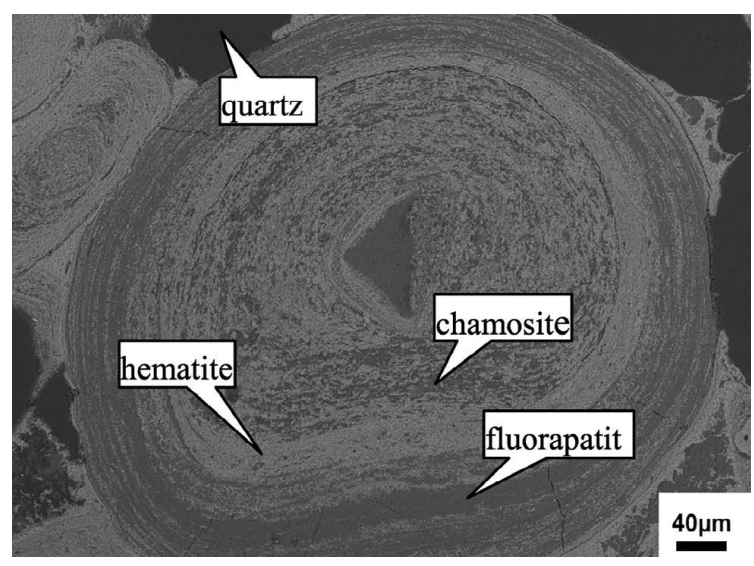

Fig. 2. Microstructure of raw ore.
The reduction roasting was carried out in a muffle furnace with a temperature control programmer. Pellets were put in a graphite crucible of $600 \mathrm{~mm}$ in diameter and $800 \mathrm{~mm}$ in height. The graphite crucible was put into the furnace and held for scheduled time when the temperature arrived at $1200^{\circ} \mathrm{C}$. After that, the roasted pellets were taken out of the furnace and cooled to room temperature under ambient temperature.

Once the pellets in the crucible had cooled, the roasted pellets were crushed to $-2 \mathrm{~mm}$ and then ground to 64.80 mass $\%-0.074 \mathrm{~mm}$ using wet grinding. The XCGS-73 low intensity magnetic separator with a magnetic field intensity of 1120 Oe was used to recover metallic iron from roasted pellets. The iron concentrates obtained from the first separation were ground and magnetic separated once again with the grinding fineness 76.95 mass $\%-0.044 \mathrm{~mm}$ to produce high iron content DRI. The main evaluation index of test results were the iron content, P-content and the iron recovery of DRI. The iron recovery refers to the percentage of the total iron metal contained in the ore that is recovered into the DRI.

Iron recovery $=$

$\frac{\text { Total weight of DRI } * \text { iron content of DRI }}{\text { Total weight of raw iron } * \text { iron conten of raw iron }} * 100 \%$

\subsection{Analysis and Characterization}

The chemical analyses were conducted by China University of Geosciences (Beijing) analysis laboratory. Scanning Electron Microscope with Energy Dispersive Spectrum (Carl Zeiss EVO18) analyses were carried out on samples mounted in epoxy resin and polished. Phases present in the samples were identified by Rigaku DMAX-RB X-ray Diffract Meter ( $\mathrm{Cu}$ target).

\section{Results and Discussion}

\subsection{The Effect of $\mathrm{Ca}(\mathrm{OH})_{2}$}

The effect of $\mathrm{Ca}(\mathrm{OH})_{2}$ dosage on the reduction of highphosphorus oolitic hematite was investigated. The experiments were conducted at a condition of temperature $1200^{\circ} \mathrm{C}$, roasted time $40 \mathrm{~min}$ and coal dosage $25 \mathrm{mass} \%$. The dosages of coal and additives are expressed by a percentage that refers to their mass ratio to the raw ore. The experimental results are shown in Fig. 3 .

The results in Fig. 3 show that (1) the content of phosphorus in the DRI decreases with increasing dosage of $\mathrm{Ca}(\mathrm{OH})_{2}$. A DRI with 0.30 mass $\%$ phosphorus can be obtained without $\mathrm{Ca}(\mathrm{OH})_{2}$. When the dosage of $\mathrm{Ca}(\mathrm{OH})_{2}$ increases to 15 mass $\%$, the content of phosphorus decreases to $0.14 \mathrm{mass} \%$, and then the dephosphorization effect maintained stable; (2) The recovery of iron increases with increasing dosage of $\mathrm{Ca}(\mathrm{OH})_{2}$, when $\mathrm{Ca}(\mathrm{OH})_{2}$ dosage increases from 0 mass $\%$ to 15 mass $\%$ the iron recovery increases from 86.58 mass $\%$ to 92.13 mass $\%$. But, when $\mathrm{Ca}(\mathrm{OH})_{2}$ dosage further increases, the iron recovery maintain stable; (3) The addition of $\mathrm{Ca}(\mathrm{OH})_{2}$ is not conducive to the grade of the DRI, especially when $\mathrm{Ca}(\mathrm{OH})_{2}$ dosage is more than 10 mass $\%$, the iron content falls sharply with the increase of the content of $\mathrm{Ca}(\mathrm{OH})_{2}$.

So it can be concluded that $\mathrm{Ca}(\mathrm{OH})_{2}$ dosage has a great 


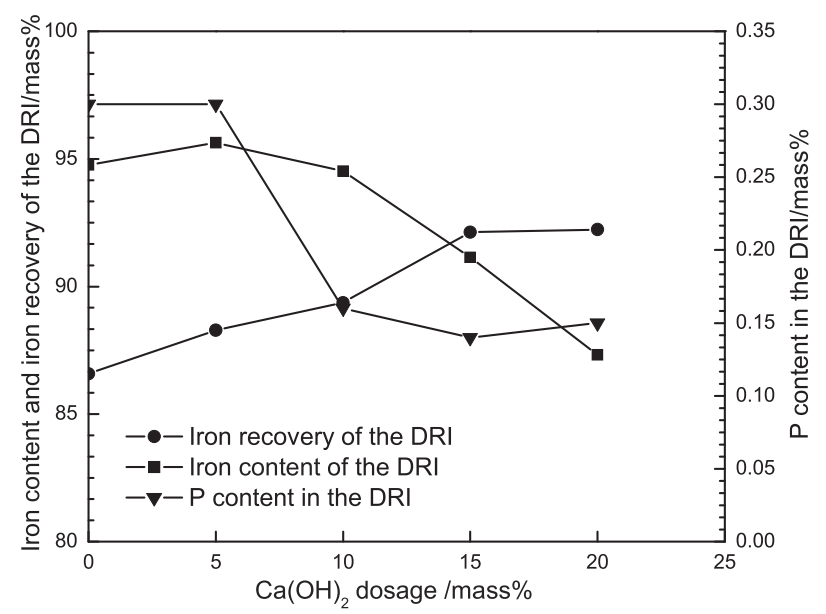

Fig. 3. Effect of $\mathrm{Ca}(\mathrm{OH})_{2}$ dosage on reduction of high-phosphorus oolitic hematite.

influence on the reduction of hematite. An appropriate $\mathrm{Ca}(\mathrm{OH})_{2}$ dosage can improve the recovery of iron and decrease the content of phosphorus in the DRI. Excessive $\mathrm{Ca}(\mathrm{OH})_{2}$ fails to further increase the recovery of iron and decrease the phosphorus content of DRI, it can leads to reducing the iron content sharply. The optimal dosage of $\mathrm{Ca}(\mathrm{OH})_{2}$ is 15 mass $\%$.

\subsection{The Effect of $\mathrm{Na}_{2} \mathrm{CO}_{3}$}

The tests above proved that although the addition of $\mathrm{Ca}(\mathrm{OH})_{2}$ can decrease the phosphorus content of DRI, the phosphorus content in the iron products is still 0.14 mass $\%$ even in the optimal $\mathrm{Ca}(\mathrm{OH})_{2}$ dosage condition. On this basis, in order to obtained DRI with less than 0.1 mass $\%$ phosphorus, different dosages of $\mathrm{Na}_{2} \mathrm{CO}_{3}$ were added together with the same $\mathrm{Ca}(\mathrm{OH})_{2}$ dosage of 15 mass $\%$ in the reduction roasting, the other experimental conditions (temperature, roasted time, coal dosage etc.) are same as the previous experiments. The result is presented in Fig. 4.

Figure 4 shows that the content of phosphorus in the DRI decreases from 0.14 mass $\%$ to 0.07 mass $\%$ and the iron content of the DRI increases from 91.14 mass $\%$ to 93.28 mass $\%$ with increasing dosage of $\mathrm{NaCO}_{3}$ from 0 mass $\%$ to 3 mass $\%$. In addition, the addition of $\mathrm{Na}_{2} \mathrm{CO}_{3}$ has no significant effect on the recovery of iron in this condition. A DRI with 0.07 mass $\%$ of phosphorus is obtained by adding 3 mass $\%$ $\mathrm{Na}_{2} \mathrm{CO}_{3}$ and 15 mass $\% \mathrm{Ca}(\mathrm{OH})_{2}$, while the grade of iron is 93.28 mass $\%$ with a recovery of 92.30 mass $\%$. The result is superior to the results of previous reports. ${ }^{8-10)}$

\section{Characteristics of Roasted Pellets}

In order to investigate the phase translation and the morphological changes of iron-bearing minerals and fluorapatite at different roasting conditions. SEM with EDS and XRD were used.

\subsection{Without Any Additive}

Figure 5(a) shows the XRD patterns of roasted pellet roasted at $1200^{\circ} \mathrm{C}$ without any additives. It can be seen from Fig. 5(a) that hematite is reduced to metallic iron and the diffraction peak of fluorapatite disappears, in addition, some anorthite and unreacted quartz were observed. This

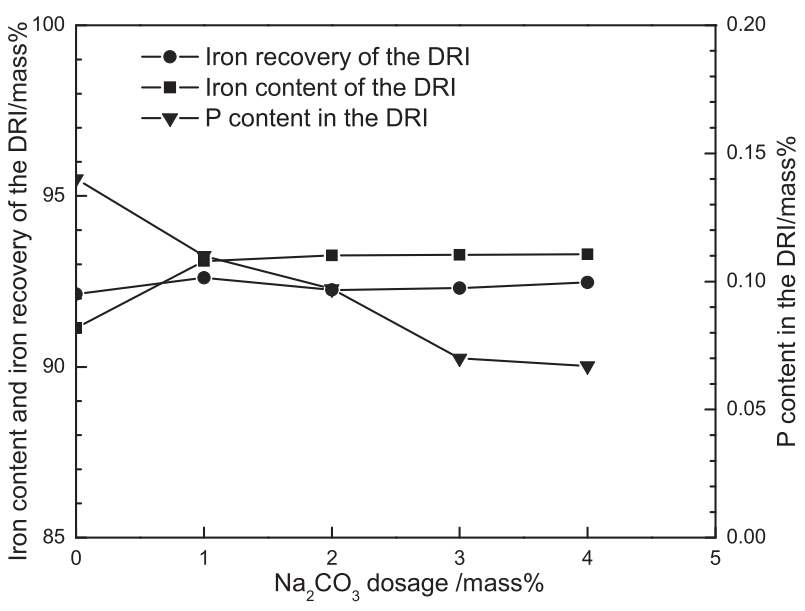

Fig. 4. Effect of $\mathrm{Na}_{2} \mathrm{CO}_{3}$ dosage on reduction of high-phosphorus oolitic hematite.

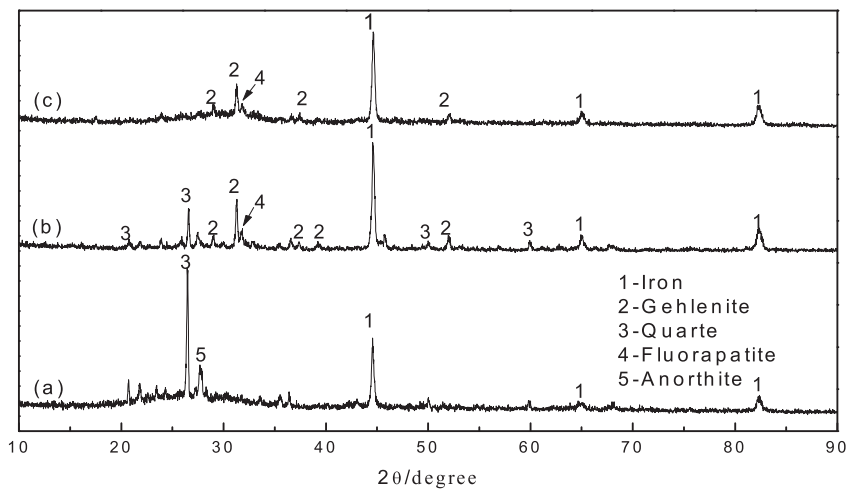

Fig. 5. XRD pattern of roasted pellets: (a) without additives; (b) with 15 mass $\% \mathrm{Ca}(\mathrm{OH})_{2}$; (C) with 15 mass $\% \mathrm{Ca}(\mathrm{OH})_{2}+3$ $\operatorname{mass} \% \mathrm{Na}_{2} \mathrm{CO}_{3}$.

shows that when additive was not at presence, the reduction of fluorapatite can occur at temperature of $1200^{\circ} \mathrm{C}$.

The chemical reaction of the reduction of phosphate can be summarized as

$$
\begin{gathered}
\mathrm{Ca}_{10}\left(\mathrm{PO}_{4}\right)_{6} \mathrm{~F}_{2}+15 \mathrm{C}+9 z \mathrm{SiO}_{2} \rightarrow \\
3 \mathrm{P}+15 \mathrm{CO}+9\left[\mathrm{CaO}\left(\mathrm{SiO}_{2}\right) z\right]+\mathrm{CaF}_{2}
\end{gathered}
$$

It is believed that the reaction occurs at above $1100^{\circ} \mathrm{C}$ and the limiting step appears to be diffusion of phosphorus-bearing species to a carbon particle where reaction occurs at the range from $1100^{\circ} \mathrm{C}$ to $1250^{\circ} \mathrm{C}$. Silica plays an important role in promoting the reaction by providing a thermodynamic driving force and modifying the melting phenomena. ${ }^{12-15)}$

Figure 6 shows SEM image and EDS of the roasted pellet without any additives. As shown in Fig. 6(a), hematite was reduced to metallic iron and metallic iron particles gathered so that the oolitic structure was completely destroyed. Figures 6(b) and 6(c) show the dispersion of Fe and $\mathrm{P}$ in the observed area, respectively. It can be seen that the majority of Fe overlaps with P. Moreover, the result of point analysis of the metallic iron (Point 1) shows that it contains a high content of $\mathrm{P}$, which could be explained that some fluorapatite was reduced to $\mathrm{P}$ and the $\mathrm{P}$ smelt into metallic iron. Since the $\mathrm{P}$ in metallic iron cannot be removed by physical separation, DRI obtained by magnetic separation contains high phosphorus content. 

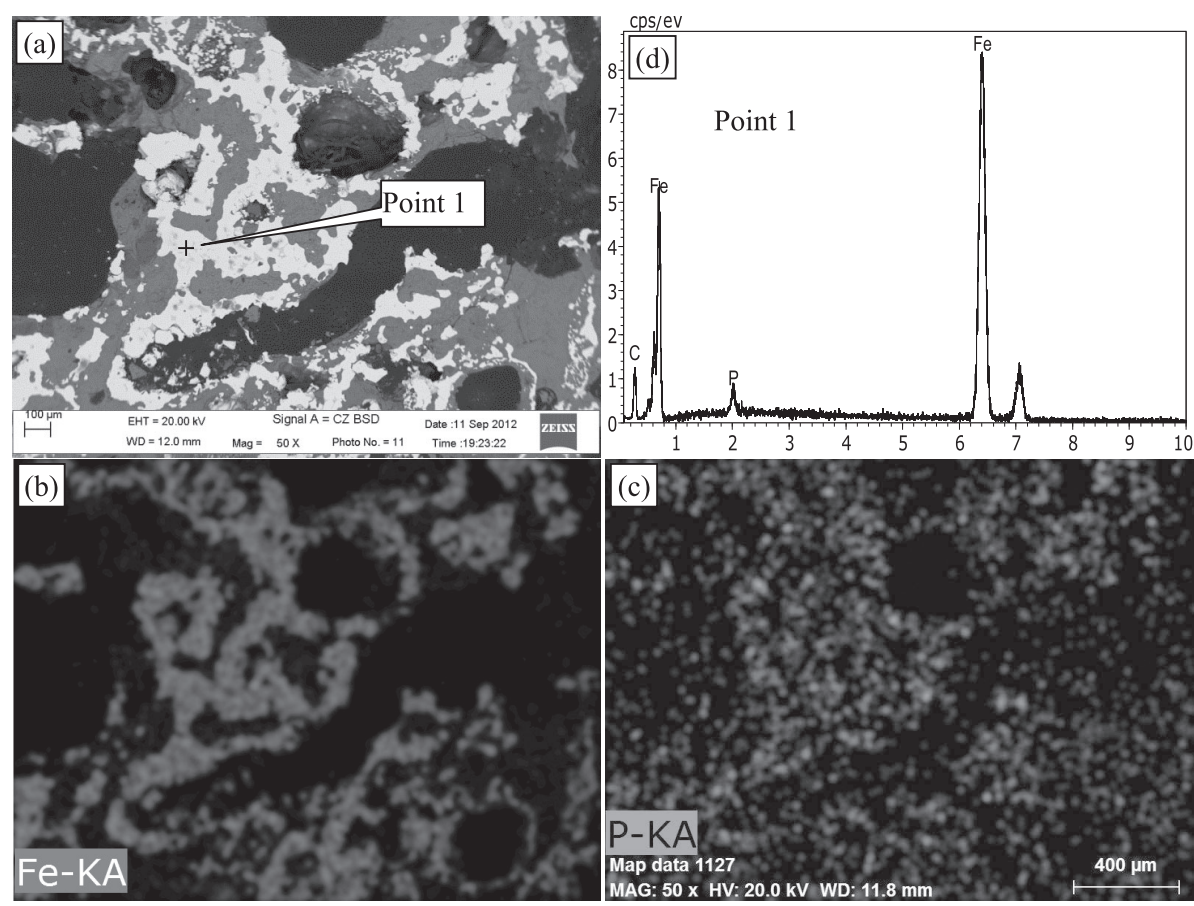

Fig. 6. SEM image and EDS results of roasted pellet without additives.
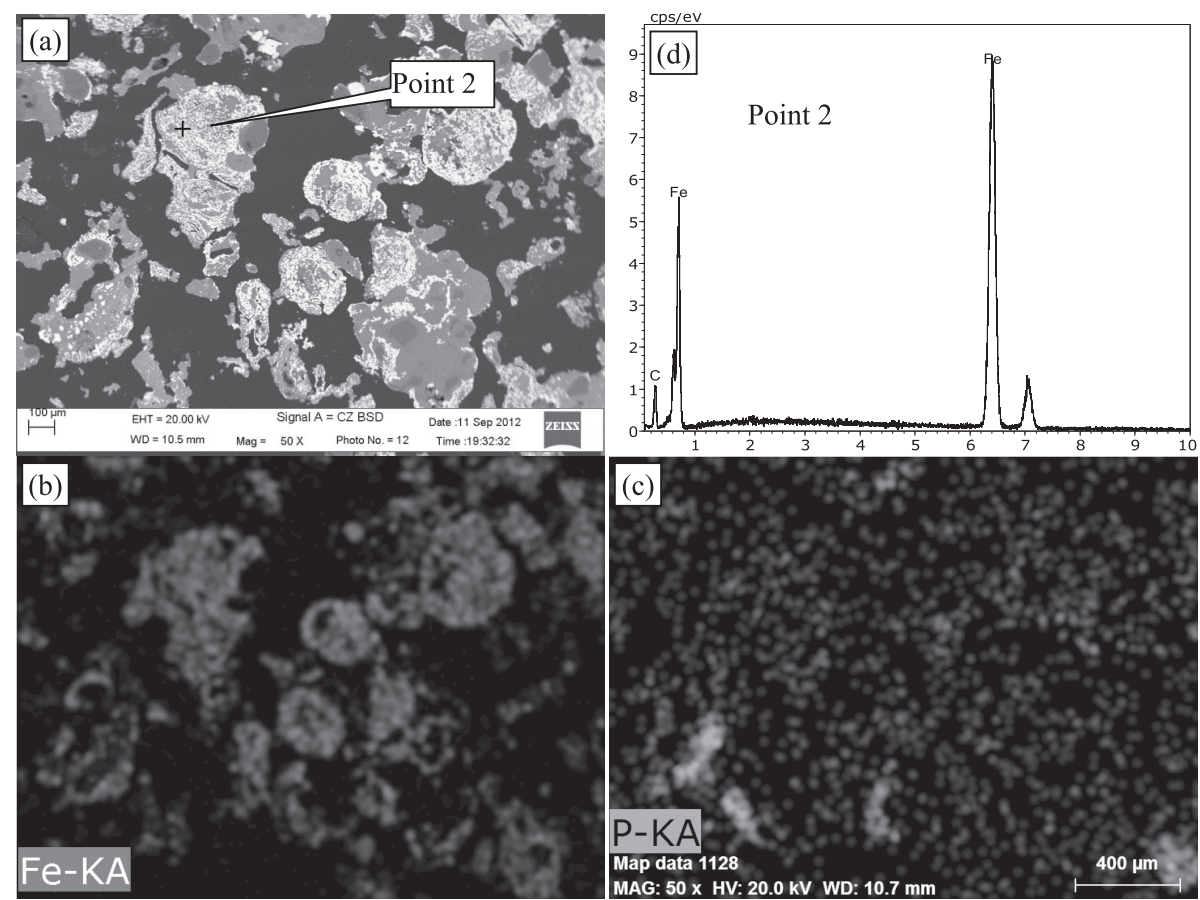

Fig. 7. SEM image and EDS results of roasted pellet with 15 mass $\% \mathrm{Ca}(\mathrm{OH})_{2}$.

\subsection{The Roasted Pellet with 15 mass\% $\mathrm{Ca}(\mathrm{OH})_{2}$}

$\mathrm{X}$-ray diffraction pattern of the roasted pellet with 15 mass $\% \mathrm{Ca}(\mathrm{OH})_{2}$ is presented in Fig. 5(b), which shows that (1) the diffraction peak of metallic iron increases markedly with 15 mass $\% \mathrm{Ca}(\mathrm{OH})_{2}$ compared with the roasted pellets without additives (Fig. 5(a)). This is due to the fact that $\mathrm{CaO}$, dissociated from $\mathrm{Ca}(\mathrm{OH})_{2}$, can replace the $\mathrm{FeO}$ from fayalite, which increases the reducing reaction activity of $\mathrm{FeO}$, and as a result, the reduction of iron oxide can be promoted; ${ }^{16)}$ (2) The diffraction peak of fluorapatite still exists, which proves that the reduction of fluorapatite is hindered by $\mathrm{Ca}(\mathrm{OH})_{2}$; (3) The diffraction peak of quartz reduces significantly and gehlenite appears with 15 mass $\% \mathrm{Ca}(\mathrm{OH})_{2}$, this is attributed to that the $\mathrm{CaO}$ dissociated from $\mathrm{Ca}(\mathrm{OH})_{2}$ reacts with quartz and Al-bearing mineral in the raw ore to form gehlenite. The reaction leads to the reduction of quartz content in the roasted pellets. On account of that quartz can promote the reduction of fluorapatite, the decrease of quartz content may not benefit for the reduction of fluorapatite.

Figures 7 and 8 show the SEM image and EDS results from a roasted pellet with 15 mass $\% \mathrm{Ca}(\mathrm{OH})_{2}$. It can be seen from Fig. 7(a), the melting phenomena is slighter and the the size of iron particles formed are smaller compared to that without $\mathrm{Ca}(\mathrm{OH})_{2}$ (Fig. 6(a)), and oolitic structure in the raw 


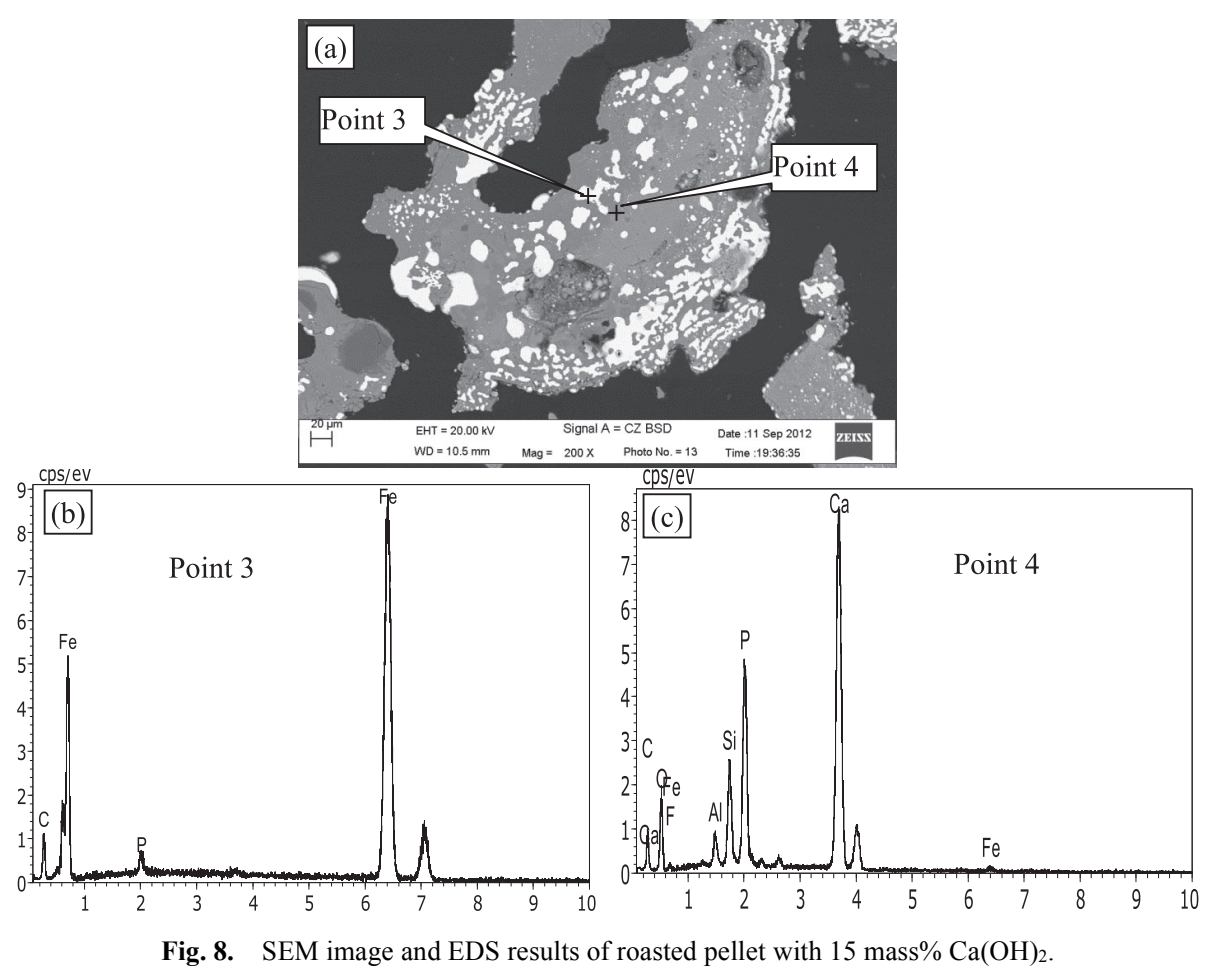

ore was not completely destroyed. It is because that $\mathrm{Ca}(\mathrm{OH})_{2}$ decomposes into $\mathrm{CaO}$ and $\mathrm{H}_{2} \mathrm{O}$ at high temperature, since $\mathrm{CaO}$ can promote the reduction of iron oxide, $\mathrm{FeO}$ content in the slag will reduce and less low melting point materials will form which in turn improve the melting point and viscosity of the slag. As a result, the diffusion of mass in the slag is limited, and thereby the growth and aggregation of metallic iron is hindered in the reduction roasting process. The liberation of iron particles from slag thus hindered by adding $\mathrm{Ca}(\mathrm{OH})_{2}$, which may be the main reason why the iron content of DRI decrease with increasing the dosage of $\mathrm{Ca}(\mathrm{OH})_{2}$.

The EDS mappings of $\mathrm{Fe}$ and $\mathrm{P}$ in the observed area are shown in Figs. 7(b) and 7(c), respectively. It is observed that the majority of $\mathrm{Fe}$ is not overlaps with $\mathrm{P}$ content, phosphorus is mainly concentrated in the oolite almost the same with that in the raw ore. In addition, the result of point analysis of the metallic iron (Point 2) shows that it does not contain P. Combined with the result of XRD pattern, it can be concluded that the reduction of fluorapatite is inhibited by adding $\mathrm{Ca}(\mathrm{OH})_{2}$ which hinders the diffusion of phosphorusbearing species to a carbon particle where reaction occurs. What's more, the reduction of quartz content roasted pellet may be not favorable to the reduction of fluorapatite. So less $P$ will generate and smelt into metallic iron. Thus the content of phosphorus in DRI decreases with increasing the dosage of $\mathrm{Ca}(\mathrm{OH})_{2}$. However, the iron particles (Point 3) which close to the phosphorus-rich region was found to contain a small amount of $\mathrm{P}$, as shown in Figs. 8(a)-8(c). It showed that there was still a small amount of fluorapatite reduced and $\mathrm{P}$ smelt into metallic iron.

So it can be concluded that $\mathrm{Ca}(\mathrm{OH})_{2}$ can not only increases the degree of iron reduction, but also decreases the degree of fluorapatite reduction.

\subsection{The Roasted Pellet with 15 mass $\% \mathrm{Ca}(\mathrm{OH})_{2}$ and 3 mass \% $\mathrm{Na}_{2} \mathrm{CO}_{3}$}

The XRD pattern of roasted pellet with 15 mass $\% \mathrm{Ca}(\mathrm{OH})_{2}$ and 3 mass $\% \mathrm{Na}_{2} \mathrm{CO}_{3}$ shows that the diffraction peak of quartz disappears, as shown in Fig. 5(c), this shows that most of the quartz take part in reaction in the present of $\mathrm{Na}_{2} \mathrm{CO}_{3}$. Meanwhile, the diffraction peak of fluorapatite still exists.

Figures 9 and 10 show SEM images and EDS results of roasted pellet with 15 mass $\% \mathrm{Ca}(\mathrm{OH})_{2}$ and 3 mass $\%$ $\mathrm{Na}_{2} \mathrm{CO}_{3}$. It can be seen from Fig. 9(a) that the size of iron particle is coarser than that in the roasted pellet without $\mathrm{Na}_{2} \mathrm{CO}_{3}$ (Fig. 7(a)), and the oolitic structure was destroyed. This is due to the fact that $\mathrm{Na}_{2} \mathrm{CO}_{3}$ reacts with $\mathrm{SiO}_{2}$ to form some low melting point materials, these low melting point materials appear in liquid phase in the course of reduction which is beneficial for the metallic iron to diffuse and aggregate. ${ }^{17)}$ The separation of iron particles from slag is thus improved by adding $\mathrm{Na}_{2} \mathrm{CO}_{3}$ and thereby the content of phosphorus in the DRI decreases and the iron content increases.

Figures 9(b) and 9(c) show that the majority of Fe is not overlaps with $\mathrm{P}$ in the observed area. The result of point analysis of the metallic iron particle shows that $\mathrm{P}$ has not been detected even in the metallic iron (Point 6) which close to the fluorapatite, as shown in Figures 10(a)-10(c). So, it can be inferred that the addition of $\mathrm{Na}_{2} \mathrm{CO}_{3}$ restrains the reduction of fluorapatite further at the presence of 15 mass $\%$ $\mathrm{Ca}(\mathrm{OH})_{2}$. This may be explained from two aspects. On the one hand, $\mathrm{Na}_{2} \mathrm{CO}_{3}$ reacts with quartz. On the other hand, the presence of $\mathrm{Na}_{2} \mathrm{CO}_{3}$ leads to the generation of liquid phase which accelerate the quartz reacting with $\mathrm{CaO}$ and other components in raw ore. As the depletion of quartz, the reduction of fluorapatite will be restricted.

In summary, the presence of $\mathrm{Na}_{2} \mathrm{CO}_{3}$ not only creates a favorable condition for the liberation of metallic irons from 

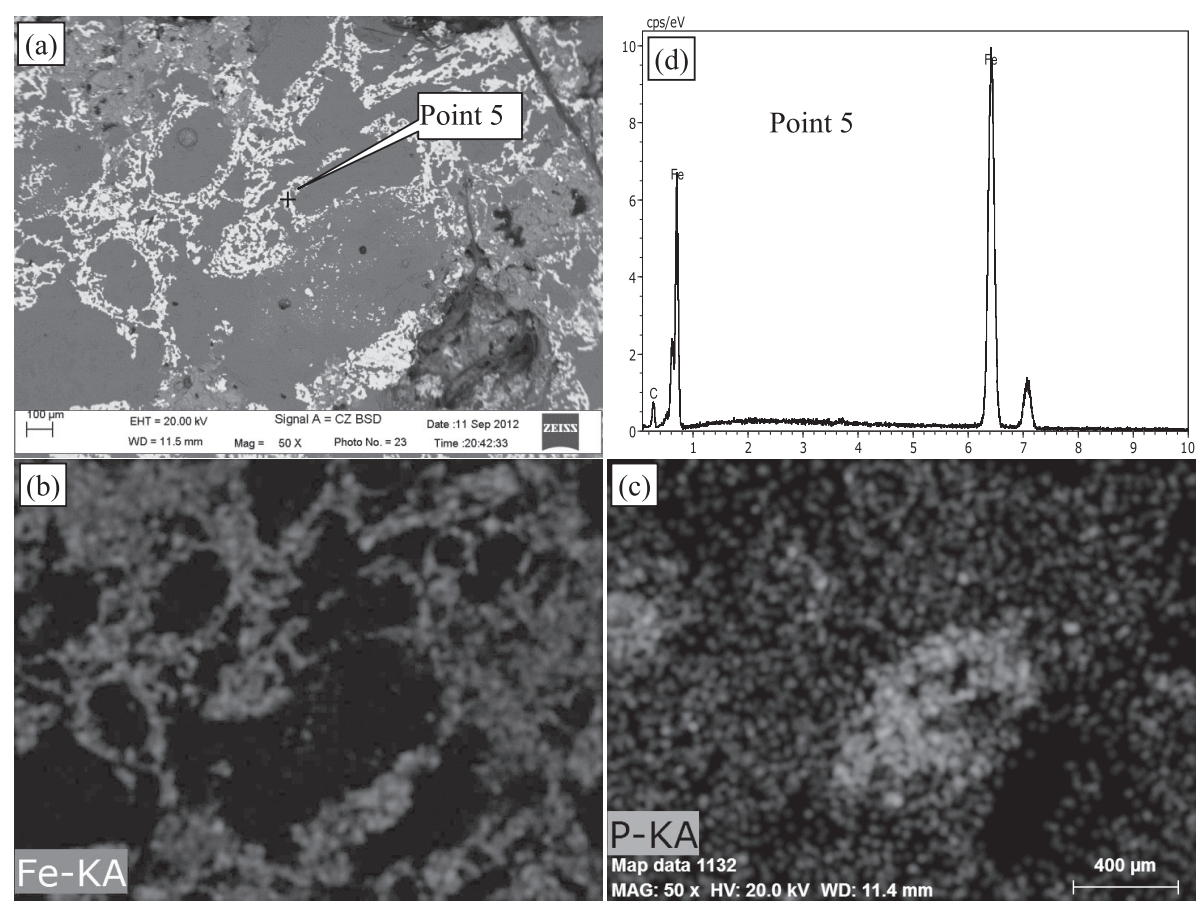

Fig. 9. SEM images and EDS results of roasted pellet with 15 mass $\% \mathrm{Ca}(\mathrm{OH})_{2}$ and 3 mass $\% \mathrm{Na}_{2} \mathrm{CO}_{3}$.

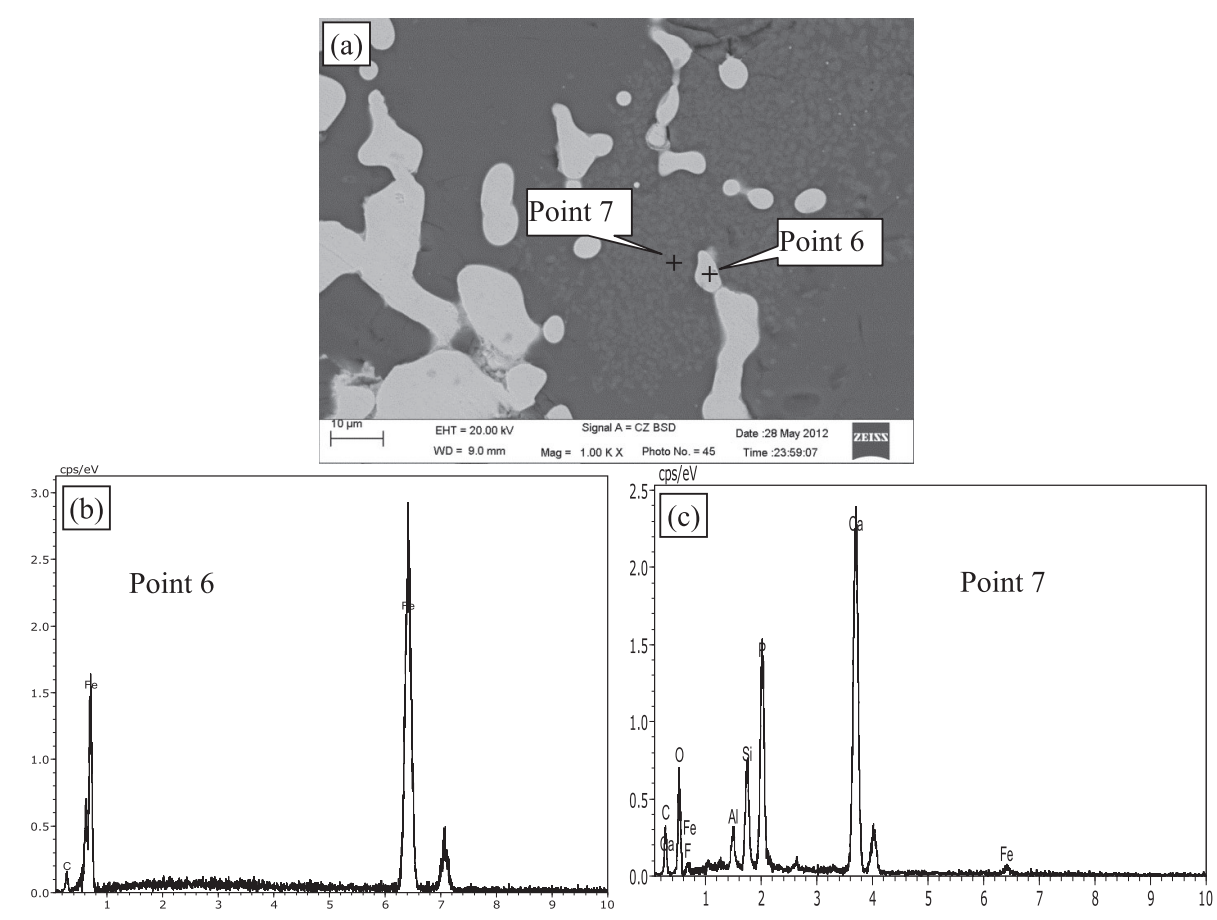

Fig. 10. SEM image and EDS results of roasted pellet with 15 mass $\% \mathrm{Ca}(\mathrm{OH})_{2}$ and 3 mass $\% \mathrm{Na}_{2} \mathrm{CO}_{3}$.

slag but also inhibits the reduction of fluorapatite at the presence of $15 \mathrm{mass} \% \mathrm{Ca}(\mathrm{OH})_{2}$. Under the optimal conditions, phosphorus remained as fluorapatite in the slag and can be removed by ground and magnetic separation.

\section{Conclusions}

From the present investigation, the following conclusions can be drawn:

(1) Without any additive and at the temperature of $1200^{\circ} \mathrm{C}$, fraction of fluorapatite in the raw ore is reduced to $\mathrm{P}$ by carbon and the phosphorus entering into metallic iron particle results in the high phosphorus content of DRI.

(2) A DRI with 93.28 mass $\% \mathrm{Fe}$, and 0.07 mass $\% \mathrm{P}$ can be obtained at a recovery of 92.30 mass $\%$ by adding 15 mass $\% \mathrm{Ca}(\mathrm{OH})_{2}$ and 3 mass $\% \mathrm{Na}_{2} \mathrm{CO}_{3}$ to the raw ore.

(3) The presence of $\mathrm{Ca}(\mathrm{OH})_{2}$ restrains the reduction of fluorapatite and promotes the reduction of hematite. The mechanism of $\mathrm{Ca}(\mathrm{OH})_{2}$ restraining the reduction of fluorapatite can be explained from two aspects. On the one hand $\mathrm{Ca}(\mathrm{OH})_{2}$ increases the melting point and viscosity of slag which in turn deteriorates the conditions of solid-solid reaction in the slag and thereby restrains the reduction of fluorapatite. On the other hand the addition of $\mathrm{Ca}(\mathrm{OH})_{2}$ leads to 
the consumption of quartz and thus restrains the reduction of fluorapatite.

(4) At the presence of 15 mass $\% \mathrm{Ca}(\mathrm{OH})_{2}$, the $\mathrm{Na}_{2} \mathrm{CO}_{3}$ exerts a positive effect for iron particle growth and aggregation which improve the conditions of separation of metallic iron and slag. At the same time, that $\mathrm{Na}_{2} \mathrm{CO}_{3}$ accelerates the consumption of quartz, which may restrain the reduction of fluorapatite.

\section{Acknowledgements}

The authors wish to express their thanks to the National Science Fund of Chinese (Grant No.51134002 and No.51074016) for financial support for this research.

\section{REFERENCES}

1) U. Srivastava and S. K. Kawatra: Miner. Process. Extr. Metall. Rev., 30 (2009), 361.

2) Y. Kobayashi and S. Kodama: ISIJ Int., 52 (2012), 960.

3) D. Liu: Metal. Mine., 8 (2009), No. 391, 12.

4) X. G. Bi. Y. C. Huang, Y. Jin and W. Xiong: Henan Metallurgy., 15
(2007), 3.

5) H. F. Yang, L. L. Jing and B. G. Zhang: J. Hazardous Mater., 185 (2011), 1405.

6) S. J. Bai, S. M. Wen, D. W. Liu, W. B. Zhang and Y. J. Xian: ISIJ Int., 51 (2011), 1601.

7) T. Jiang, M. D. Liu, G. H. Li, N. Sun, J. H. Ceng and G. Z. Qiu: Chin. J. Nonferrous Met., 20 (2010), 565.

8) D. W. Yang, T. C. Sun, H. F. Yang, C. Y. Xu, C. Y. Qi and Z. X. Li: J. Univ. Sci. Technol. Beijing, 32 (2010), 969.

9) C. Y. Xu, T. C. Sun, C. Y. Qi, Y. L. Li, X. L. Mo, D. W. Yang, Z. L. Li and B. L. Xing: Chin. J. Nonferrous Met., 21 (2011), 680.

10) Y. L. Li, T. C. Sun, C. Y. Xu and Z. H. Liu: J. Cent. South Univ. Technol. Natural Sci., 43 (2012), 827.

11) J. C. Zhou, Z. L. Xue, H. F. Zhang and Z. Q. Li: Ironmaking Steelmaking, 26 (2007), 40.

12) F. Leder, H. Reiss, J. Mu, J. Megy, R. A. Hard and W. C. Park: Metall. Trans. B, 17B (1986), 869

13) J. Mu, F. Leder, W. C. Park, R. A. Head, J. Megy and H. Reiss: Metall. Trans. B, 17B (1986), 861

14) L. K. Jiang, B. Fu, L. Y. Qiu and J. C. Song: J. Sichuan Univ. Eng. Sci., 5 (1995), 1.

15) L. K. Jiang, B. Fu, L. Y. Qiu and J. C. Song: J. Sichuan Univ. Eng. Sci., 1 (1995), 1

16) X. H. Huang: Iron and Steel Metallurgy Principles, 2nd ed., Metallurgy Industry Press, Beijing, (2011), 304.

17) X. H. Huang: Iron and Steel Metallurgy Principles, 2nd ed., Metallurgy Industry Press, Beijing, (2011), 215. 